\title{
Evaluating co-innovation principles in a fundamental bioprotection research programme addressing challenges to potato production
}

\author{
J. Vereijssen ${ }^{1}$, T.A. Williams ${ }^{1}$, N.M. Park ${ }^{2}$, M-C. Nielsen ${ }^{1}$ and N.M. Agnew ${ }^{2}$ \\ ${ }^{1}$ The New Zealand Institute for Plant \& Food Research Limited, Private Bag 4704, \\ Christchurch Mail Centre, Christchurch 8140, New Zealand \\ ${ }^{2}$ The New Zealand Institute for Plant \& Food Research Limited, Private Bag 1401, \\ Havelock North 4130, New Zealand \\ Corresponding author: Jessica.Dohmen-Vereijssen@plantandfood.co.nz
}

\begin{abstract}
Co-innovation can be effective for addressing complex challenges involving multiple stakeholders who hold diverse viewpoints and perceptions. Addressing these challenges requires changes at various scales. However, there is limited systematic research on how co-innovation can work in different projects and what impacts it can have on the outcome. Co-innovation principles were tested for their potential to enhance the impact delivered by a fundamental research project investigating options for managing the tomato potato psyllid/Candidatus Liberibacter solanacearum complex in potato crops. A series of interviews and workshops were undertaken to increase interactions within the programme and with industry stakeholders. Additionally, a member of the research team, trained in co-innovation theory and practice, took a leadership role in planning and delivering technology transfer activities. The effects of bringing co-innovation principles to the programme are described, in particular the challenges encountered when introducing these concepts into a fundamental research programme.
\end{abstract}

Keywords agricultural innovation system, tomato potato psyllid, Bactericera cockerelli, impact delivery, primary sector.

\section{INTRODUCTION}

Primary Innovation research programme

Co-innovation is an iterative process that brings together knowledge from many stakeholders, along with changes in technology, markets, regulations and other practices that support the commercialisation and implementation of knowledge to improve production, exports, profits and/or the environment (Leeuwis 2004; Klerkx et al. 2012). Co-innovation practice is context-specific and adaptive: how and when co-innovation is implemented must be tailored to the particular situation, and may change over time (Klerkx et al. 2010; Neef \& Neubert 2011). While this is increasingly acknowledged, there is relatively limited comparative research documenting the effects of experiments with coinnovation in a range of research programmes, although this knowledge would stimulate learning (Thiele et al. 2007).

A New Zealand Government-funded research 
programme, Primary Innovation (PI), initiated in 2012, is undertaking a comparative analysis of co-innovation in research programmes in partnership with various important New Zealand horticultural and agricultural sectors. In this paper we focus on the first aim of PI: to implement and evaluate the effectiveness of co-innovation approaches in the primary sector (Botha et al. 2014). The PI programme became involved in five New Zealand primarysector research projects (innovation projects) where attempts have been made to apply a coinnovation approach (Vereijssen et al. 2016). One of those research projects is the six-year multidisciplinary New Zealand Governmentfunded research programme 'Realising Potato Export Growth' (RPEG), henceforth referred to as the innovation project.

Different roles for people or organisations are recognised in co-innovation, e.g. as co-developers of knowledge, champions of institutional change, and entrepreneurs experimenting with new business models. The two important roles for the research described here were: 1) a reflexive monitor who gets the project team where it needs to go, identifies conflict, collects data and evaluates, facilitates, provides feedback to the project team and identifies the right stakeholders to be involved in the project (van Mierlo et al. 2010); and 2) a knowledge or innovation broker who generally emerges in response to a perceived suboptimal degree of connectivity between relevant actors due to market or innovation system failures. Brokers establish the connections between those who develop knowledge or innovations and those who will use the knowledge or innovation (Klerkx \& Leeuwis 2009).

\section{Innovation project}

The innovation project addresses the tritrophic interaction between the vector tomato potato psyllid (TPP, Bactericera cockerelli) (Hemiptera: Triozidae), the plant pathogenic bacterium Candidatus Liberibacter solanacearum (CLso), and the host plant. The vector/pathogen complex became a major problem in New Zealand potato crops in 2008 following the incursion of TPP to New Zealand in 2006. This bacterium is the putative causal agent of zebra chip (ZC) disease of potato tubers (Liefting et al. 2008), which makes them unsuitable for processing (Secor \& Rivera-Varas 2004; Munyaneza et al. 2007), causes disease in seed tubers (Berry et al. 2011; Pitman et al. 2011), and is perceived to affect the taste of fresh market potatoes as well as their internal appearance. The insect/pathogen complex is also an important economic pest of other solanaceous crops, including tamarillo, eggplant and outdoor- and greenhouse-grown tomato and capsicum. The aim of the research programme is to assist the New Zealand potato industry to realise export growth by addressing the pressing need for economically and environmentally sustainable control solutions for the TPP/CLso complex. The innovation project entails fundamental research in three, mainly laboratory-based, Research Aims (RAs): 1) TPP sensory cues; 2) TPP population genetic variability, and 3) host plant response to TPP and CLso, while the fourth RA is 'Knowledge transfer to stakeholders'. When the programme began, the science RAs each had an RA leader, while the fourth RA did not. The innovation project commenced in October 2013, and the PI programme became involved in June 2014.

The rationale for selecting the RPEG programme as an innovation project were: 1) timeframe aligned with PI's timeframe for intervention; 2) the RGEP Programme Leader was interested in maximising impact from the research programme and had well-established working relationships with several members of Plant \& Food Research's (PFR) PI team; 3) the PI programme is a linked contract to the RPEG programme; 4) the RPEG programme's Impact Statement provided us with an opportunity to work towards establishing an innovation network for the project that included a range of stakeholders; and 5) the REPG programme was well-connected to other TPP/CLso research at PFR.

The aim of this paper is to discuss the effects over time of applying co-innovation principles to a fundamental research programme and to 
answer two questions: 1) can implementation of co-innovation principles enhance the impact of TPP/CLso research in New Zealand potato production? and 2) what are the barriers and opportunities for implementing co-innovation principles in a multi-disciplinary, fundamental research programme?

\section{METHODS}

Research on the innovation project was conducted between June 2014 and March 2017. The PI team acted as participant observers in the innovation project, leading to a strong familiarity with the programme and the people associated with it.

\section{Monitoring and evaluation}

To generate evidence of the effects of testing co-innovation principles in the programme, the PI team used feedback sheets, kept notes of meetings, and had a reflexive monitor present at some RA leaders' meetings. Additionally, the PI team conducted a timeline analysis (van Mierlo et al. 2010) to reflect on key events since the incursion of TPP into New Zealand and how those had shaped and influenced the context for the innovation project.

\section{Evaluation interviews}

The Wieczorek \& Hekkert analysis framework (2012), was adapted to create a set of quantitative and qualitative questions that probed the scope of co-innovation and team members' experiences relative to the concept. This framework had been used successfully by the PI team previously to analyse a completed research programme (Park et al. 2015).

The first round of face-to-face interviews was conducted in March 2015. The purpose was to obtain baseline data for the PI programme on the interviewee's perception of co-innovation and their understanding of the goals of the innovation project, including identifying any barriers to co-innovation. Ten people were interviewed: scientists working in the innovation project and people in science management roles closely aligned to the project (Table 1). The interviews consisted of semi-structured questions (Patton 1990) and were approximately one hour in duration. They were conducted by the same two people, who also recorded the sessions. Then the interviews were transcribed, and reviewed and signed off by the interviewees. Narratives from interviewees were aligned to the Wieczorek \& Hekkert analysis framework (2012), which identifies the functions and structures in an agricultural innovation system that are essential pre-requisites for co-innovation. Relevant data were loaded in a Microsoft ${ }^{\circledR}$ Excel spreadsheet. The PI team then identified the main themes that emerged, particularly any barriers to innovation associated with the absence of critical functions and structures. Results were discussed with the innovation project Programme Leader and summarised at an RA leaders' meeting.

The second round of face-to-face interviews was conducted in March to April 2017 with the aim of evaluating what had changed over time, positively or negatively, and any changes that were due to efforts to introduce co-innovation concepts to the research team. Ten scientists and science managers were interviewed (Table 1), seven of whom had been interviewed in the first round. Staff changes within the innovation project and identification of new key actors in the innovation project meant that some interviewees provided responses for the first time.

The PI team compared the results of each round of interviews to identify shifts in thinking, interactions, research direction or progress towards impact delivery as a result of applying co-innovation principles, and particularly to find evidence to address the two questions noted above.

Table 1 Number of people in each profession interviewed in the first (January 2015) and second (March - April 2017) round of interviews.

\begin{tabular}{lcc}
\hline Profession & $\begin{array}{c}\text { Interview } \\
\text { round 1 }\end{array}$ & $\begin{array}{c}\text { Interview } \\
\text { round 2 }\end{array}$ \\
\hline $\begin{array}{l}\text { Scientist } \\
\text { Science } \\
\text { management role }\end{array}$ & 6 & 5 \\
\hline
\end{tabular}




\section{RESULTS}

A timeline analysis was constructed identifying key events, externally as well as within PFR (Figure 1), to enable opportunities for increased interactions and knowledge exchange and diffusion to be identified and tested with the interviewees. Teulon et al. (2015) also described a timeline of significant events between 2005 and 2010, documenting events associated with the incursion of TPP.

From the results of the first round of interviews, the PI team identified: 1) a lack of communication within the innovation project as a potential barrier to co-innovation; and 2) that opportunities to exchange knowledge with external stakeholders (within PFR or externally) could support the delivery of impact.

The key activities undertaken to address these two themes were:

1. Resourcing and providing leadership to $R A$ 1.4 (Technology transfer). The PI team identified that resourcing and leading RA 1.4 'Technology transfer' could help those working in the innovation project to share their knowledge or understanding gained with stakeholders. The PI team organised an RA 1.4 workshop during which a stakeholder engagement plan was discussed to identify research results that might be ready for extension, key target audiences and mechanisms for communicating research discoveries.

2. Embedding skills in co-innovation in the innovation project. Scientist $\mathrm{X}$, a named researcher in the innovation project, was part of the PI team and engaged in research with PI team members. Scientist X trained in co-innovation concepts, learned from other innovation projects and presented research results at an international conference. Her understanding of the value of coinnovation increased and built on a recognisable skill set in technology transfer with end users. Scientist $\mathrm{X}$ had the full confidence of the Programme Leader and her research colleagues before the innovation project began, and had a strong profile with internal and external stakeholders. She contributed her understanding of co-innovation and the importance of increasing interactions with stakeholders to members of the innovation project.

3. Supporting interactions with industry through a two-day meeting of research and industry. The PI team identified an opportunity
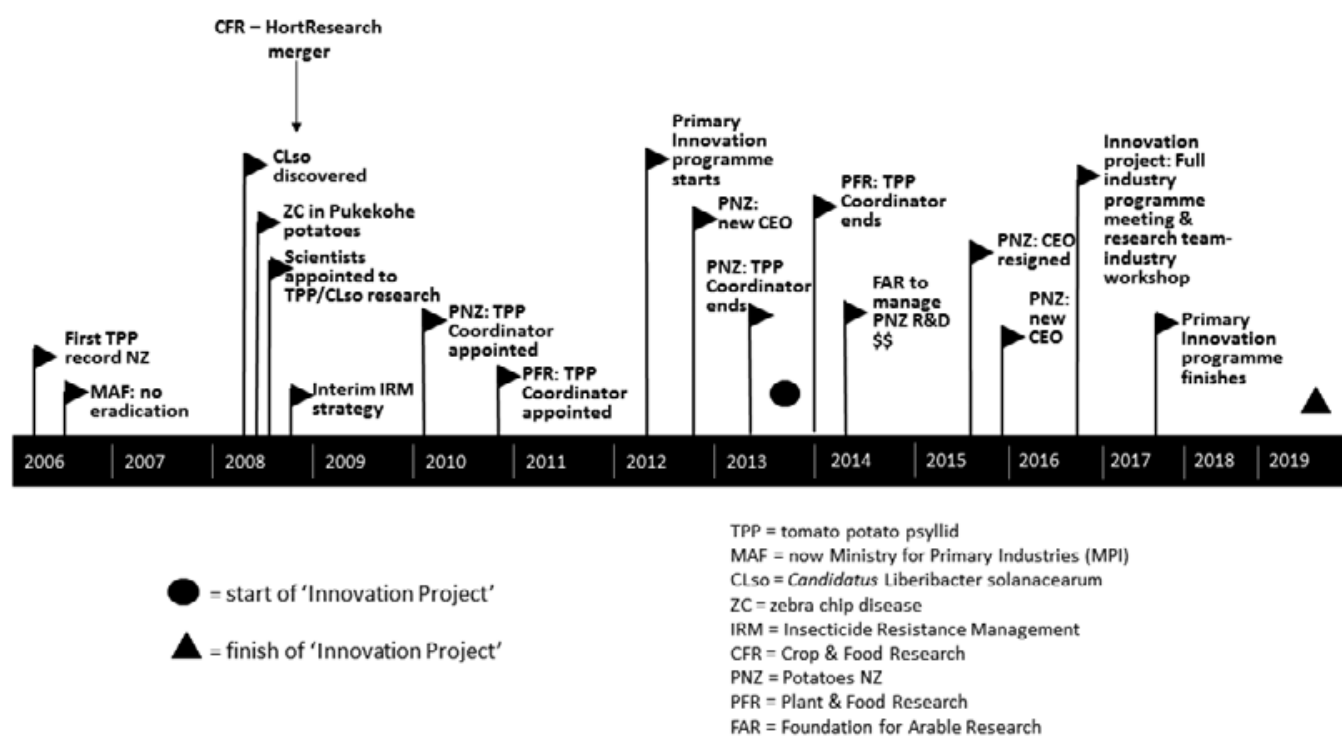

TPP = tomato potato psyllid

MAF = now Ministry for Primary Industries (MPI)

$\mathrm{CL}$ so $=$ Candidatus Liberibacter solanacearum

ZC = zebra chip discase

IRM = Insecticide Resistance Management

CFR $=$ Crop \& Food Research

PNZ = Potatoes NZ

PFR $=$ Plant \& Food Research

FAR = Foundation for Arable Research

Figure 1 Timeline representing key events from the first find of tomato potato psyllid in New Zealand, and the start and finish of the Primary Innovation programme and the Innovation Project. 
to support the Programme Leader in her efforts to create a research team meeting to review and plan research directions within the wider programme. Practical help was offered, along with encouragement to engage industry representatives in the meeting. With the support of the innovation project's Business Manager and Scientist X, a total of 45 industry and science representatives attended a meeting in September 2016 to hear about relevant discoveries within the innovation project as well as related potato research that had potential application to farming practices.

Key themes to emerge from the second series of interviews, undertaken to evaluate the effects of these three activity areas and the extent to which co-innovation theory and practice had enhanced the innovation project's progress towards impact, are outlined below.

\section{Increased awareness of the meaning of the co-innovation concept}

Interviewees, particularly those in support roles, described co-innovation more confidently and in a way that resembled the concepts developed in PI. They appeared to better understand the need for wider engagement and interactions with stakeholders earlier in the innovation process. There was still a sense that others were responsible for driving those interactions and for any change from the usual linear, technology transfer-style of operating. This belief stems from a lack of time to engage; a lack of capability to manage and follow through on the necessary processes; the belief that science explores unknowns and cannot formulate advice without statistically significant evidence; a sense that scientists can be trusted to set priorities directions/pursuits; and that delivering on contracted milestones is the key driver of activity. Despite these barriers, views were clearly expressed about the importance of co-innovation, such as:

"And so actually before you embark on a research project, talking to potential users of the technology and people who might be interested actually talk to them about what they might need, what they might want, and so they're actually able to contribute to your thinking and design of the research in the early stages".

\section{Changed interactions between programme members and external stakeholders}

While the impact statement for the innovation project seemed elusive and aspirational during the first interview round, it has provided a common focus for those working in RAs who have needed time to explore, discover new knowledge and address information gaps. The innovation project has been required to evaluate their progress towards the impact target annually when meeting the funding body's annual reporting requirements. Occasional RA leader meetings have also created opportunities to describe (rather than analyse) science progress. The two-day programme meeting in September 2016 also created an opportunity to reflect and evaluate research progress in relation to the impact target. Interviewees reported that the current knowledge base was growing and was reaching a point where sharing knowledge was starting to inform the various RAs: "[...] I didn't really see what was the connection between us in terms of Research Aims and what we are doing." This has taken more than four years to achieve. Knowledge exchange is happening at an informal and unstructured level. In part, it has been driven by a new RA leader who has connected with others in the innovation project to create context for the research for which she is now responsible. The challenge of building relationships with external users who would apply the new technologies emerging from the programme was expressed by one scientist in the following way:

"For me it's knowing the people. So those relationships take a long time to develop. So it's having the time to go to field days or industry meetings, being introduced to those people and building up that relationship, so it's a lot of time ... Scientist $X$ has been really good at field days and has introduced me to everyone so Scientist $X$ knew who might be there and who I should meet. So I think that was a really key thing. I guess those discussions should be happening continuously. You can't just stop. However, barriers associated with 
resources to interact with end-users were identified too. "But it is having that time and it's not time that's ever coded for or sort of allowed it's been my experience. If you're wanting to go to a meeting somewhere else, how do you pay for that?"

Understanding how their own research discoveries directly contributed to the delivery of the impact statement remained difficult for some researchers, although they were confident they had generated new knowledge. The delivery of specific tools to aid TPP management, such as a cultivar, attractant or new TPP monitoring system, remained a work-in-progress.

Changes in external stakeholders had also created interest in the value of the research being undertaken, with new roles in executive management in the potato sector as well as in an agency commissioned to manage potato research investments on behalf of the potato sector. These changes focused attention on accountability, decision making and efficiencies within the innovation project. They also influenced pathways for outputs and impacts, e.g. an industry newsletter now includes a section on potato research.

\section{Targeting outputs to meet end-users' needs}

A number of outputs were described during the interviews, most of which described fundamental knowledge development that interviewees felt required further exploration before they could be communicated to end-users. There is no mechanism for sharing information on these outputs currently, although the process of producing an annual report for the funding body will prompt that data collection. There was overall acknowledgement that outputs remained to be formalised in the last 17 months of the programme:

"There have been a number of grower type articles, not that many. ... I trusted that we would produce papers and I still trust that we will produce papers but yes, they're slow coming".

\section{Delivering the contracted impact by the end of the innovation project}

The full programme meeting in September 2016 created a new pathway for outputs to flow to the industry. It built relationships within the team and within PFR as well as with the industry, creating knowledge-exchange opportunities. The innovation project research team discussed progress and there was an opportunity to make reprioritisation decisions on Day Two of the programme. However, any changes were left for those working within each RA to determine. No other opportunities for the team to reflect and reassess had been created since that full programme meeting.

The introduction of Scientist $\mathrm{X}$ as RA 1.4 leader was intended by the PI team to create a new pathway to impact through increased communications and technology transfer. However, beyond one initial article for the NZGROWER magazine, there has been both a lack of suitable content to communicate via the pathway and few events in the 2016-17 season at which to trigger interactions between researchers and the industry.

Many interviewees commented positively on the value of the full programme meeting in terms of creating an opportunity to engage with the industry:

"I think it was more than just a diary moment. ... I think that meeting did a lot of what it was supposed to do. Kind of a little step change ... Just getting the people together. The people in the Research Programme were keen and interested and gung-ho. We did have the presence of the industry people that made for some extra good conversations and some extra good questioning."

"I suspect it [the innovation project] might need another phase, as these knowledge creation ones often do. I suspect it will probably spinout too if the Sustainable Farming Fund would fund another potato TPP project, but that kind of more applied, how do we transfer/what's the gap still in terms of the knowledge we've generated and being able to translate that to practical on farm solutions. So I think there's probably another step in the process yet."

[In terms of repeating the full programme meeting ...] "Not annually for this programme but annually for the industry and actually I saw Industry Person $Z$ one day last week ... and I said 
"what do you think about [it]; because we had that meeting and it was successful" and the industry people that were there said "give us more please, we liked this". So my thought was that we won't do this programme every year because I don't think we've got that quantum of progress to keep the industry happy and not think "I've heard this all before I'm bored". A really science-driven meeting like that would almost have the same kind of two-aim thing: would be unashamedly talking science so that the scientists have those chances to make links but also the industry people have a chance to hear us unashamedly talking potato science."

\section{Ongoing barriers to impact}

All interviewees identified ongoing barriers to having impact associated with engaging with the industry, including a lack of time, not knowing who to talk to within the industry, and not having definitive tools or advice ready for industry uptake.

"I think time is probably the only resource I would say is probably lacking, and it's always lacking. If you feel over-stretched and over-stressed for example ... it's hard to not just look at the minimum instead of looking at what can be done." [...] "That we have resources and we have leftover steam so to speak to say 'what can I do better?' not just 'what do I have to do as an absolute minimum to move forward?"”

"[...] when we have enough time that may be useful but if we don't have extra time we're probably not going to do that [take on board discoveries from other RAs]."

There was a clear sense that the kinds of skills demonstrated by Scientist $\mathrm{X}$ require special dedication to extract information, analyse it and adapt it for particular end-users. The ability of the industry, in turn, to engage with scientists was also commented upon:

"I think probably we have a role to play in educating our customers about being involved at an early stage of research and what their role could be and what the expectations could be, so that you actually set those at the start and it might be that it's a different person than say your R\&D Manager or whoever we traditionally have in that early phase, it might be someone different, but I think having those conversations with our clients and helping them understand 'the role' we need them to play in that early stage of science is different to when it becomes applied and ready to translate out is something we could do."

And in terms of meeting in the middle, the view was expressed that there was a great deal more to be done to create meaningful engagement:

"We've done this side [science providers] and now the client reporting one [looking at what industry wants from scientists], and they have all involved trying to engender behaviour change and I think that's where we're still tripping up. We still haven't worked out how we can successfully change behaviour in [a particular science provider] ... and I think that's something we need to think about. Because that's the only way any of these things are going to have real impact and success, is to get people to participate, appreciate and do this stuff. We just need to get buy-in."

\section{DISCUSSION}

Based on the responses from the second round of interviews, the three actions taken following the first round of interviews varied in their success. Efforts to encourage more technology transfer and knowledge exchange through RA 1.4 is a work-in-progress, with research outputs expected over the final 17 months of the innovation project. Embedding co-innovation skills within the innovation project in the form of Scientist X had been very successful, with a number of research team members and support staff commenting on the positive interactions she had generated while also recognising the challenges Scientist X faces when working in this innovation broker role. The full programme meeting, particularly Day One at which industry representatives were present, was unanimously considered a positive development. On Day Two, the opportunity to reflect as a science team on changes in direction or resourcing within the innovation project to enhance its ability to deliver impact was not fully realised.

The interviewees recognised that co-innovation had much to offer in terms of increasing 
interactions amongst stakeholders and ultimately enhancing the innovation project team's ability to deliver impact from their TPP/CLso research. Based on the barriers they identified to adopting co-innovation practices individually, it is clear that changes in scientists' skills, training and mind sets are required. Resourcing also need to be addressed, particularly time and organisational commitment to valuing engagement in balance with science excellence. The willingness of industry partners to engage with scientists, including taking time to understand the complexity of the concepts involved and the degree of risk involved in implementing new concepts and practices, remains an issue. Continuing pressure around accountability and performance may result in milestone-chasing behaviour at the expense of taking time to reflect jointly on progress and to pursue the most impactful science and pathway to generate value for New Zealand. These are not new issues nor are they specific to this project, but the value of the co-innovation approach is to document and review them in light of increasing pressure to deliver impact from RS\&T investments.

This research identified a number of barriers and opportunities to implementing coinnovation principles in a multi-disciplinary, fundamental research programme. It is clearly a challenge to apply co-innovation when knowledge gaps are substantial and time is required to address them. Setting impact expectations on research programmes that are addressing fundamental knowledge gaps places considerable pressure on research teams. Instead, investing in innovation projects that combine experts in commercialisation, communication, and science along with new roles such as evaluation specialists and innovation brokers would provide scientists with the support they need to develop impact pathways and have meaningful engagement with industry, enhancing impact for New Zealand as a whole.

\section{ACKNOWLEDGEMENTS}

We thank the Ministry of Business, Innovation and Employment, and New Zealand dairy farmers through DairyNZ (RD1429) for funding the 'Colearning and co-innovation for increased impact' project (CONT-30071-BITR-AGR); the Primary Innovation team for discussions and insights; and Melanie Davidson and Gail TimmermanVaughan for reviewing this manuscript.

\section{REFERENCES}

Berry N, Thompson S, Taylor N, Wright P, Shah F, Walker M, Beard S, Jorgensen N, Butler R, Thompson S, Scott I, Pitman AR 2011. The impact of $C a$. Liberibacter infected seed tubers on potato production in New Zealand. The 11th Annual Zebra Chip Reporting Session: 178-182.

Botha N, Klerkx L, Small B, Turner JA 2014. Lessons on transdisciplinary research in a co-innovation programme in the New Zealand agricultural sector. Outlook on AGRICULTURE 43: 219-223.

Klerkx L, Leeuwis C 2009. Establishment and embedding of innovation brokers at different innovation system levels: Insights from the Dutch agricultural sector. Technological forecasting and social change 76: 849-860.

Klerkx L, Aarts N, Leeuwis C 2010. Adaptive management in agricultural innovation systems: The interactions between innovation networks and their environment. Agricultural Systems 103: 390-400.

Klerkx L, van Mierlo B, Leeuwis C 2012. Evolution of systems approaches to agricultural innovation: concepts, analysis and interventions. In: Darnhofer I, Gibbon D, Dedieu B eds. Farming systems research into the 21st century: The new dynamic. Springer Netherlands, Dordrecht. Pp. 457-483.

Leeuwis C 2004. Communication for rural innovation: rethinking agricultural extension. Blackwell Science Ltd., Oxford, UK. 412 pp.

Liefting LW, Perez-Egusquiza ZC, Clover GRG, Anderson JAD 2008. A new 'Candidatus Liberibacter' species in Solanum tuberosum in New Zealand. Plant Disease 92: 1474-1474. 
Munyaneza JE, Crosslin JM, Upton JE 2007. Association of Bactericera cockerelli (Homoptera : Psyllidae) with "zebra chip," a new potato disease in southwestern United States and Mexico. Journal of Economic Entomology 100: 656-663.

Neef A,NeubertD2011.Stakeholder participation in agricultural research projects: a conceptual framework for reflection and decisionmaking. Agriculture and Human Values 28: 179-194.

Park NM, Williams TA, Walker JTS, Butcher MR, Turner JA, Botha N, Vereijssen J, Taylor NM 2015. Enhancing innovation and technology transfer in the New Zealand apple industry learnings from Apple Futures. New Zealand Plant Protection 68: 291-298.

Patton MQ 1990. Qualitative evaluation and research methods. Second edition. SAGE Publications Inc., USA. 532 pp.

Pitman AR, Drayton GM, Kraberger SJ, Genet RA, Scott IAW 2011. Tuber transmission of 'Candidatus Liberibacter solanacearum' and its association with zebra chip on potato in New Zealand. European Journal of Plant Pathology 129: 389-398.

Secor GA, Rivera-Varas VV 2004. Emerging diseases of cultivated potato and their impact on Latin America. Revista Latinoamericana de la Papa (Suplemento) 1: 1-8.
Teulon D, Hill M, Zydenbos S 2015. Responding to the establishment of new pests and diseases: What can be learnt from tomato potato psyllid and Candidatus Liberibacter solanacearum in New Zealand? New Zealand Plant Protection 68: 76-84.

Thiele G, Devaux A, Velasco C, Horton D 2007. Horizontal evaluation: Fostering knowledge sharing and program improvement within a network. American Journal of Evaluation 28: 493-508.

van Mierlo B, Regeer B, van Amstel M, Arkesteijn M, Beekman V, Bunders J, de Cock Buning T, Elzen B, Hoes A, Leeuwis C 2010. Reflexive monitoring in action. A guide for monitoring system innovation projects. Wageningen University; Athena Institute, VU University Amsterdam. 106 pp.

Vereijssen J, Srinivasan M, Dirks S, Fielke SJ, Jongmans C, Agnew NM, Klerkx L, Pinxterhuis JB, Moore J, Edwards P, Brazendale R, Botha N, Turner JA 2016. Addressing complex challenges using a coinnovation approach: lessons from five case studies in the New Zealand primary sector. 12th European International Farming Systems Association (IFSA) Symposium.

Wieczorek A, Hekkert M 2012. Systemic instrument for systemic innovation problems: A framework for policy makers and innovation scholars. Science and Policy 39: 74-87. 